\title{
Situational Analysis and Expert Evaluation of the 1000 Days: Nutritional and Health Status in 4 Countries in Latin America
}

\author{
Andrea Ramírez ${ }^{*}$, Sofía Velasco ${ }^{1 *}$, Oscar Bernal1, José Fernando Vera-Chamorro ${ }^{2}$, \\ Gabriela Olagnero ${ }^{3}$ \\ ${ }^{1}$ Escuela de Gobierno Alberto Lleras Camargo, Universidad de los Andes, Bogotá, Colombia \\ ${ }^{2}$ Division of Pediatric Gastroenterology, Hepatology and Nutrition, Hospital Universitario Fundación \\ Santa Fe de Bogotá, Universidad de los Andes, Bogotá, Colombia \\ ${ }^{3}$ Scientific Coordination for Latin America, Danone Nutricia Early Life Nutrition, Buenos Aires, Argentina \\ Email: *aravamd@gmail.com, *obernal@uniandes.edu.co
}

Received 9 February 2016; accepted 15 March 2016; published 18 March 2016

Copyright (C) 2016 by authors and Scientific Research Publishing Inc.

This work is licensed under the Creative Commons Attribution International License (CC BY).

http://creativecommons.org/licenses/by/4.0/

(c) (i) Open Access

\section{Abstract}

Background: The first 1000 days of life, including pregnancy and the first $\mathbf{2}$ years of age have been considered essential for an adequate development and growth. Several studies have stated that malnutrition during pregnancy and not having a normal birth weight have negative impact on childhood and adulthood, and contribute to burden of disease. Adequate information on this matter provides the possibility for making recommendations on health and nutrition policies. Objective: The aim is to describe the nutritional status during the first $\mathbf{1 0 0 0}$ days in four countries of Latin America: Colombia, Argentina, Chile and Brazil. Methods: The analysis consists of two complementary approaches: 1) An extensive search on published and gray literature and a critical analysis of secondary data bases was conducted in Colombia, Argentina, Chile and Brazil following a standardized methodology in 2013. Maternal and child nutritional status, breast feeding, nutritional deficiencies, and dietary habits during the first $\mathbf{1 0 0 0}$ days were the variables of interest; 2) Information gaps were identified, interviews to local experts from academia, government and hospitals were conducted to fill each of the countries information gap. Data was organized in an online data base called NutriPl@net. Results: Despite the inherent country differences, the nutritional challenges during the first $\mathbf{1 0 0 0}$ days are similar. Obesity prevalence is increasing in pregnant women. Under weight remains a problem in all 4 countries, with the highest prevalence in Argentina. Over weight prevalence is highest in Chile and obesity prevalence in Brazil. Micronutrient deficiencies in pregnant women have been described, especially high for folic acid, iron, zinc, vitamins A, B6, B12, C, E and riboflavin. Moreover, in the region, anemia is the most common micronutrient deficiency during pregnancy. Gestational diabetes, hypertension, obesity and pre-eclampsia 
are major causes of maternal, perinatal and infant morbidity and mortality. Conclusions: In order to understand regional and country-specific needs, it is fundamental to collect standardized information related to the nutrition status during the first $\mathbf{1 0 0 0}$ days. The low prevalence of exclusive breastfeeding and micronutrient deficiencies such as iron, zinc and vitamin $A$ as risk factors for morbidity and mortality in children 0 - 2 years old is common and priority issues in the region. Persistence of anemia despite the use of fortified foods and supplementation remains a problem, and no complete data regarding sugar, sodium and fatty acids consumption and changes in the diet and habits before, during and after pregnancy are available. The gaps that are found to justify the need for further studies including population based surveys with standardized methodology that can warrant comparability.

\section{Keywords}

\section{Breastfeeding, Infants, Nutrition, Pregnancy, Latin America}

\section{Introduction}

A critical period which includes pregnancy and the first 2 years of age and is known as the "first 1000 days" has been considered essential for the development and growth of the individual and the main window of opportunity to prevent nutritional health problems not only in childhood but also in adulthood.

Pregnancy is one of the periods of greatest nutritional vulnerability [1]. Deficit in maternal weight and some micronutrients such as calcium, omega-3 fatty acids, iron, zinc, folic acid and vitamins A, D and B have shown to influence significantly the course of pregnancy, childbirth and newborn's health. Brain development begins in pregnancy and is completed mostly during the first two years of life. Moreover, fetal and metabolic programming occurs and determines weight gain in childhood and adulthood [1]-[4].

Recent publications reveal common challenges such as suboptimal breastfeeding (not meeting the breastfeeding recommendation of the World Health Organization) [5], inadequate feeding practices, early introduction and poor quality of complementary feeding, vitamin A and iron deficiency, lack of education in nutrition and an urgent need for regional partnerships in health and nutrition in developing countries [6].

In relation to the morbidity and mortality associated with inadequate nutrition during the first 1000 days of life, it is known that every year more than 20 million babies are born with low birth weight and that about one-fifth of these babies die during the neonatal period [7]. Over a third of these deaths are attributed to maternal and child nutritional deficiencies. Maternal malnutrition contributes to 800,000 deaths per year [8] and stunting, wasting, and micronutrient deficiencies are the basis of nearly 3.1 million child deaths each year [9]. Finally, it is estimated that $45 \%$ of deaths in children less than 5 years old are associated with low birth weight, malnutrition, wasting, micronutrient deficiencies such as vitamin A and zinc and suboptimal breastfeeding. Therefore, interventions to improve the nutritional status during the first 1000 days of life can save approximately 3 million lives per year worldwide and improve health in early childhood and adulthood [8].

On one hand, receiving adequate prenatal care and micronutrient supplementation during pregnancy have shown to be effective in maternal and infant mortality reduction. On the other hand, exclusive breastfeeding until 6 months of age, micronutrient supplementation and adequate, timely and safe complementary feeding during the first two years of life have shown to prevent infant mortality and chronic diseases potentially associated with these nutritional factors in early life [1]-[7].

\section{First 1000 Days Current Status in Latin America}

The region of Latin America follows the overall trend in the increased morbidity and mortality from non-communicable diseases [10], while continuing to experience nutritional problems such as low height for age, anemia and micronutrient deficiencies in pregnant women and children between 0 - 2 years of age.

For the past decades it has been described in the literature that the Latin American countries have been experiencing a rapid demographic, epidemiological and nutritional transition. This means: 1) The fertility rate has decreased and life expectancy has risen with an increase in the elderly population; 2) The morbidity and mortality 
from chronic diseases (obesity, type 2 diabetes mellitus, and high blood pressure) are becoming public health problems and predominate over infectious diseases and; 3) Undernutrition and obesity as malnutrition extremes coexists [6] [10]-[13].

Moreover, large inequities between rural and urban areas, the coexistence of malnutrition (predominantly low height for age), anemia, vitamin A deficiency, overweight and obesity are observed in the region [14]-[16].

\section{Objective}

This project aims to describe the nutritional status during the first 1000 days of life (pregnant women and children 0 - 2 years old) in 4 countries in Latin America (Colombia, Argentina, Chile and Brazil).

\section{Methods}

Literature review, secondary databases analysis, and expert consultation. A strategy was developed to collect the most updated and current country information regarding: 1) general indicators (population and vital statistics, education, economy, environment); 2) food patterns (food consumption); 3) nutritional status (energy, macronutrients, minerals, vitamins); 4) lifestyle (physical activity, smoking, alcohol) and; 5) public health context (health system, disease prevalence, causes of death, nutritional regulations, local key actors) of pregnant and 0 - 2 year old children in Colombia, Argentina, Chile and Brazil, in the 2000-2013 period. All the information was gathered following a standardized and stepwise methodology. Topics of interest included general health issues, socio-demographic characteristics, breastfeeding practices, feeding habits, nutritional deficiencies and excesses, maternal nutritional status and morbidity during pregnancy.

The following steps were conducted in order to complete each country database:

1) Collection of socio-demographic characteristics, health status, breastfeeding, maternal nutritional status and nutritional deficiencies, dietary habits and morbidity data included: a) An extensive literature search on healthcare-related databases (PubMed, Biblioteca Virtual en Salud-BVS, Bireme and government, NGOs and scientific organizations' websites); 2) A review of gray literature obtained from sources like WHO, UNICEF, PAHO; 3) A critical analysis of information in the national nutritional surveys in each country.

2) Detection and address of information gaps (missing or outdated information).

Interview to experts were required when an information gap was detected. Experts were interviewed using a standardized guide to answer the main topics and to provide an overview of the country public health situation, programs, recommendations and concerns.

The selection of experts was made according to the information gaps. Therefore the experts had to be from the main fields of expertise (e.g. pediatricians, neonatologists, nutritionists and obstetricians) representing the academia, clinical practice or public health institutions from different geographic areas of each country were included. Local experts were selected for being key opinion leaders in the subject due to their position or background, authors of publications in the area or in-depth knowledge of the topic.

All data from the literature review and expert interviews were gathered in a database and categorized on the basis of the following headings: general country information (e.g., population and vital statistics), infant and child health and mortality, breastfeeding practices and main feeding patterns (e.g., meal frequency and staple foods), nutritional status (e.g., local nutrient recommendations and intakes), local and national health programs, and recommendations for future research and actions. Descriptive analyses were conducted.

\section{Results}

An average of 13 interviews per country was conducted with experts, ranging from 9 in Argentina and Chile to 20 in Brazil. These interviews were face-to-face in Brazil, Argentina and Chile, and whenever possible in Colombia, otherwise by phone.

\subsection{First 1000 Days Current Status in Latin America Country's General Information}

During the search and data collection period (2000-2013) and from the data reported in the literature, it was found that in the last decades there was a reduction in birth rate, a slight increase in the elderly population and a gradual drop in total fertility rate demonstrating the nutritional transition. Table 1 provides a description of the characteristics of the 4 Latin American countries. 
Table 1. Population demographic and general health characteristics.

\begin{tabular}{|c|c|c|c|c|}
\hline & Argentina & Brazil & Chile & Colombia \\
\hline Population in millions (year) ${ }^{*}$ & 42.202 .935 (2013) & 200.361.925 (2013) & 17.619.708 (2013) & $48.321 .405(2013)$ \\
\hline Birth rate (/1000 population) ${ }^{*}$ & $17.9(2013)$ & $15.0(2012)$ & $14.0(2012)$ & $19.0(2012)$ \\
\hline Fertility rate (births per woman) ${ }^{*}$ & 2.2 & 1.8 & 1.8 & 2.3 \\
\hline Death rate (/1000 population) ${ }^{*}$ & $7.7(2012)$ & $6.0(2012)$ & $6.0(2012)$ & $6.0(2012)$ \\
\hline Low weight at birth $<2500$ gr (\%) & $7.4(2013)$ & $8.4(2010)$ & $5.9(2006)$ & $6.0(2010)$ \\
\hline Under 5 yr mortality (/1000 live births) ${ }^{*}$ & $14.0(2010)$ & $20.6(2009)$ & $8.7(2010)$ & 20.1 (2009) \\
\hline Life expectancy at birth (yr) ${ }^{*}$ & $76(2012)$ & $74(2012)$ & $80(2012)$ & $74(2012)$ \\
\hline GINI index ${ }^{* * *}$ & $0.45(2010)$ & $0.52(2012)$ & $0.52(2009)$ & $0.56(2010)$ \\
\hline Poverty gap 2 USD a day $(\%)^{* * *}$ & $1.3(2011)$ & $3.3(2012)$ & $0.8(2011)$ & $4.7(2012)$ \\
\hline GDP per capita (US\$-2012) ${ }^{* * *}$ & $14.7(2013)^{* * *}$ & $11.34(2012)$ & $15.45(2012)$ & $7.75(2012)$ \\
\hline Access to sanitation $(\%)^{* * *}$ & 97 (2012) & $81(2012)$ & $99(2012)$ & $80(2012)$ \\
\hline Maternal deaths* & $245(2013)^{*}$ & $2100(2013)$ & $55(2013)$ & $760(2013)$ \\
\hline Obesity general population (\%) & $20.8(2013)$ & $11.1(2008)$ & $25.1(2010)$ & $16.5(2011)$ \\
\hline Overweight general population (\%) & $37.1(2013)^{* *}$ & $50.6(2012)$ & $39.3(2010)$ & $32.3(2005)$ \\
\hline Literacy $(\%)^{*}$ & $98(2012)$ & $91(2012)$ & 99 (2009) & $94(2011)$ \\
\hline Vaccination coverage ${ }^{* * * *}$ & 95 & 95 & 89 & $80(2012)$ \\
\hline Skilled delivery attendance $\left.(\%)^{* * * *}\right|^{*}$ & $98(2012)$ & $98(2011)$ & $100(2011)$ & 99 (2013) \\
\hline Cesarean section $(\%)^{* * * * *}$ & 32 & 43.8 & 37 & 34.4 \\
\hline
\end{tabular}

${ }^{*}[17]-[21] ;{ }^{* *}[22] ;{ }^{* * *}[23] ;{ }^{* * * *}[17][18][24][25] ;{ }^{* * * * *}[19]$ [26] [27].

Also, that of the 4 countries Brazil has the largest population followed by Colombia, Argentina and Chile. Colombia had the highest birth, fertility rate, GINI index, poverty gap and the lowest vaccination coverage. Brazil had the highest low birth weight, under 5 mortality prevalences and number of maternal deaths. Chile had the highest life expectancy, the highest GPD per capita, access to sanitation, literacy rate, prevalence of obesity in the general population and skilled birth attendance.

\subsection{Country's Nutrition Information-Pregnant Women Characteristics}

\subsubsection{Nutritional Status}

Overweight and obesity prevalence are increasing in pregnant women population. Underweight remains a problem in all 4 countries, with the highest prevalence in Argentina. Overweight prevalence is highest in Chile and Obesity prevalence in Brazil. This shows the nutrition transition that these countries are experiencing and also the expected increase in non-communicable chronic diseases as a consequence of obesity in this population.

\subsubsection{Micronutrient Deficiencies}

In Latin America, the case of micronutrient deficiencies in pregnant women has been described, especially high for folic acid, iron, zinc, vitamins A, B6, B12, C, E and riboflavin. WHO recommends giving them supplements of these micronutrients as a way to reduce iron deficiency anemia in pregnant women [16] [28] [29].

Moreover anemia is the most common micronutrient deficiency during pregnancy in the region. An increased consumption of iron during pregnancy by supplementation has been provided in order to prevent anemia during pregnancy; however, adherence is low and recommendations vary from country to country. All countries have implemented fortified food programs intended for pregnant women and general population (flour and/or milk fortification) to reduce anemia and neural tube defects (NTDs) prevalence. In Argentina and Chile, changes in 
the prevalence and mortality of NTDs were evaluated in pregnant women before and after food fortification, results showed a significant reduction in both countries [29]-[31]. Table 2 provides a description of the nutritional status and main micronutrient deficiency in pregnant women from the 4 Latin American countries.

\subsubsection{Pregnant Women Morbidity}

Gestational diabetes, hypertension, obesity and pre-eclampsia are major causes of maternal, perinatal and infant morbidity and mortality. Prevalences are shown in Figure 1 for Argentina, Brazil and Colombia (Chile has not published information about morbidity in pregnant women for the last 10 years). It is worth mentioning a high prevalence of hypertension in Argentina and pre-eclampsia in Brazil [17]-[19] [21] [26] [28] [29] [32]-[36].

\subsection{Country's Nutrition Information-0 - 2 Year Old Children Characteristics}

\subsubsection{Breastfeeding and Complementary Feeding}

WHO recommends exclusive breastfeeding during the first 6 months of life for optimal growth, development and health. Continued breastfeeding up to two years of age or beyond confers major nutritional benefits and is an essential component of appropriate complementary feeding. Promotion of breastfeeding is seen as the most effective way to reduce child mortality [37].

Argentina followed by Chile has the highest prevalence of exclusive breastfeeding up to 6 months. Colombia has the highest mean of months of breastfeeding. In the interviews that were conducted in each country successful past experiences, adequate breastfeeding techniques education, family and social support were related to successful breastfeeding by the experts interviewed. Maternal or newborn disease, medical advice, pacifier use, maternal work, inadequate techniques, lack of knowledge about breastfeeding were related with an interruption in breastfeeding.

In relation to breastfeeding policies, all the four countries have national plans and policies to promote this practice. It is worth mentioning that Brazil has the largest human milk bank in the world, Chile extended the maternity leave to 6 months and Argentina is promoting the creation of workplace facilities to support and promote breastfeeding.

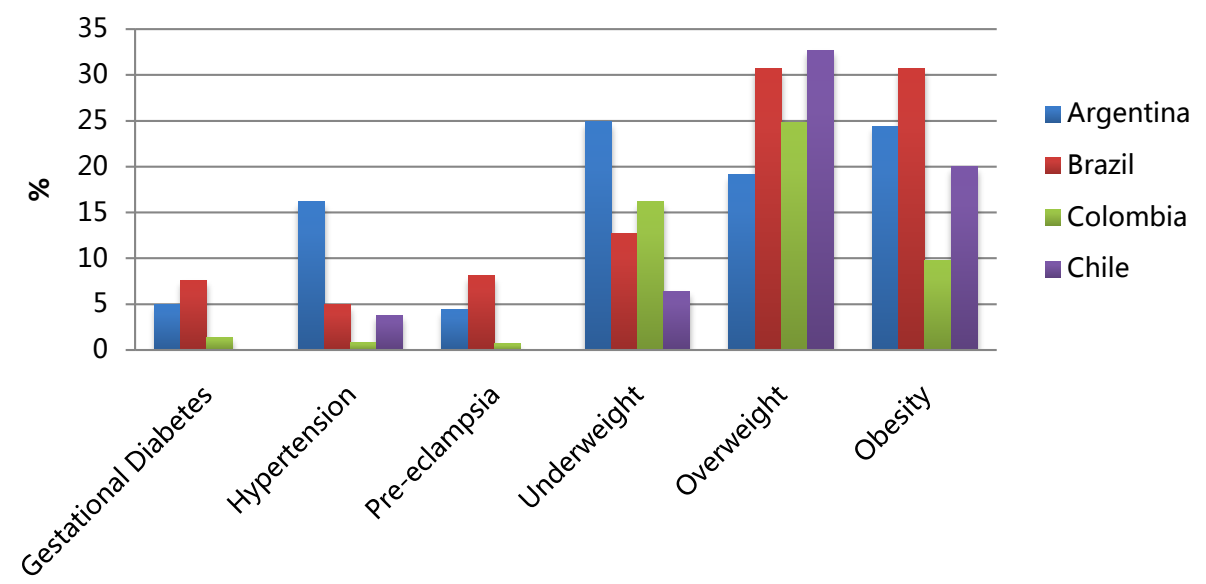

Comorbidities and malnutrition

Figure 1. Comparison of comorbidity and malnutrition during pregnancy between countries.

Table 2. 1000 day nutrition characteristics (pregnant women population).

\begin{tabular}{ccccc}
\hline & Argentina & Brazil & Chile & Colombia \\
\hline Underweight in pregnancy $(\%)^{*}$ & $24.9(2005)$ & $12.7(2012)$ & $6.4(2010)$ & $16.2(2010)$ \\
Overweight in pregnancy $(\%)^{*}$ & $19.1(2005)$ & $30.7(2012)$ & $32.7(2010)$ & $24.8(2010)$ \\
Obesity in pregnancy $(\%)^{*}$ & $24.4(2005)$ & $30.7(2012)$ & $20.0(2010)$ & $9.8(2010)$ \\
Anemia $(\mathrm{Hb}<12.4 \mathrm{mg} / \mathrm{dl})(\%)^{*}$ & $30.5(2005)$ & $29.4(2009)$ & $10.9(2008)$ & $17.9(2010)$ \\
\hline
\end{tabular}


The transition from exclusive breastfeeding to family foods, referred to as complementary feeding, typically covers the period from 6 to 18 - 24 months of age. Timely introduction of adequate and safe complementary foods at six months of age was identified by experts as a solution to fill the dietary gaps breast milk could not fulfill alone.

Complementary feeding is most frequently initiated before 6 months of age in these countries. The mean age of introduction is 2.7 months in Colombia and 5 months on average for the rest of the countries. Early dairy introduction, especially cow's milk, is a common practice in Latin America at about 3 mo and is related to nutritional problems as anemia and iron deficiency in the short term and obesity in the long term [17] [20] [32] [36].

Regarding amounts, frequency, consistency and use of a variety of foods to cover children's nutritional needs, national surveys show adequate frequency and consistency of foods. In relation to variety, a high consumption of sweet, fried and processed food with inadequate intake of fruits and vegetables was shown [17] [20] [32] [36].

\subsubsection{Nutritional Status}

The prevalence of underweight is below $10 \%$ in all countries as shown in Table 3. On the contrary, the prevalence of obesity and overweight is higher in Latin American children. Stunting has declined significantly in all countries and, with the exception of Chile where prevalence is the lowest, it is expected to continue decreasing in the coming decade (Table 3).

\subsubsection{Micronutrient Deficiencies}

Anemia, vitamin A and zinc deficiencies are among the most common deficiencies in this age group. Argentina has the highest anemia prevalence; Brazil has the highest vitamin A deficiency and Chile the highest zinc deficiency of all the 4 countries. Information was available mostly for children 0 - 11 months old or less than 5 years old, these different cutoffs limit comparisons and analysis. Therefore information for children from 0 to 2 years old was scarce.

\subsection{Public Health Policies Related to the 1000 Days}

An important number of public health policies and programs in each country were designed to impact favorably on this period as detailed in Table 4 [40].

Some impact evaluations of these programs have been conducted showing positive results on the first 1000 days. A systematic review by Cotta about the impact of the "Programa Bolsa Família" (Family Monetary Subsides Program) has shown positive results on hemoglobin and anthropometric evaluations in some studies. It has been highlighted that in order to guarantee food and nutritional security, programs require encompassing both the fight against malnutrition as well as overweight and obesity. So they can contribute more effectively to the welfare nutritional beneficiaries when combined with other interventions such as healthy eating promotion [41].

Table 3. 1000 day nutrition characteristics ( 0 - 24 months old population).

\begin{tabular}{ccccc}
\hline & Argentina & Brazil & Chile & Colombia \\
\hline Exclusive breastfeeding (at least 6 months) $(\%)$ & $54(2011)$ & $41(2010)$ & $43(2012)$ & $43(2010)$ \\
Mean of exclusive breastfeeding in months & $12.0(2005)$ & $11.2(2009)$ & NA & $14.9(2010)$ \\
Children underweight (\%) & $2.1(2005)$ & $1.7(2009)$ & $4.4(2010)$ & $3.4(2010$ \\
Children overweight (\%) & NA & NA & $24.3(2010)$ & $20.2(2010)$ \\
Children obesity (\%) & $10.2(2005)$ & $7.3(2006)$ & $8.6(2010)$ & $5.2(2010)$ \\
Anemia in children $>11-24$ mo $(\%)^{* *}$ & $29.0(2005)$ & $20.9(2009)$ & $12.0(1999)$ & $12.9(2010)$ \\
Vitamin A deficiency children $>11-24$ mo $(\%)^{* * * *}$ & $14.3(2005)$ & $17.4(2009)$ & NA & $25.2(2010)$ \\
Zinc deficiency children $>11-24$ mo $(\%)^{* * * *}$ & $11.8(2011)$ & NA & $55.0(1999)$ & $42.1(2010)$ \\
\hline
\end{tabular}

${ }^{*}$ Chile 12-24 months old, Brazil <5 years old Colombia $<5$ years old, Argentina 6 months old-23 months old; ${ }^{* * *}$ Argentina $2-5$ years old, Brazil <5 years old, Colombia 1 - 4 years old; ${ }^{* * * *}$ Argentina 12 - 23 months old, Colombia 1 - 4 years old, Chile (male 18 months old); Table references: [17] [20] [32] [36] [38] [39]. 
Table 4. Public health policies intended for the first 1000 days.

\begin{tabular}{|c|c|}
\hline & Argentina \\
\hline "Plan Nacer" (Birth Plan) [45] & $\begin{array}{l}\text { Public health insurance for pregnant women, infants and children up to } 6 \\
\text { years old without other health coverage. Launched in 2005, in June } 2012 \\
\text { reached 1,896,522 women and children. }\end{array}$ \\
\hline “Plan Sumar” (Add up Plan) [46] & $\begin{array}{l}\text { Plan Sumar Program was rolled out on } 2012 \text { and builds on } 7 \text { years of re- } \\
\text { sults-based financing experience from a maternal and child health initiative, } \\
\text { Plan Nacer. It includes children, adolescents and women up to } 64 \text { years old } \\
\text { without other health coverage. }\end{array}$ \\
\hline $\begin{array}{l}\text { “Asignación Universal por Hijo/Embarazo” (Monetary } \\
\text { Universal subsides per child/pregnancy) [47] }\end{array}$ & $\begin{array}{l}\text { Monetary subsidies: all families with children and adolescent under } 18 \text { years } \\
\text { old receive a money transfer equivalent to } 60 \mathrm{USD} \$ \text { /child. This payment is } \\
\text { for workers whose salary is under the minimum, for informal workers or } \\
\text { unemployed. The conditions for receiving it are children vaccination, regular } \\
\text { health controls and school assistance from } 5 \text { years old. Nowadays 3,500,000 } \\
\text { children are covered. Pregnant women also receive a monetary subsidy dur- } \\
\text { ing pregnancy. }\end{array}$ \\
\hline
\end{tabular}

“Programa Materno Infantil” (Maternal-infant national program) [48]

Maternal-infant national program started in 1994 with provincial and municipal delegations which includes normatives in maternal-nutrition health and distribution of whole powdered milk fortified with iron, zinc and vitamin C.

Brazil

"Programa Nacional de Suplementação de Ferro- PNSF" (National Iron supplementation program) [49]

“Programa Bolsa Família” (Family Monetary subsides Program) [41]

Promotes iron flour fortification and iron supplementation in children 6 - 18 months old.

Itis a conditional cash transfer program that provides financial aid to poor Brazilian families in order for their children to have access to school, vaccination and other services and fight poverty in the long term.

“Programa Nacional de Suplementação de Vitamina A” (Na- Promotes vitamin supplementation in children 6 - 11 months old. tional Vitamin A supplementation program) [50]

“Rede Cegonha (Stork Network)”[51].

It promotes a new model of birth attendance, birth and child health. Aims to reduce infant mortality. It is a national program led by the Ministry of health.

"Brasileirinhas e Brasileirinhos Saudáveis: Primeiros Passos para o Desenvolvimento Nacional” (Healthy Brazilians)” [52]

To Ensure all Brazilians quality of life from its beginnings, stimulating their physical emotional, cognitive and social skills and abilities. Strengthen joint efforts across the country to articulation, interaction and implementation of actions aimed at the health of women and children up to six years, stage of life known in Brazil as "Early Childhood”

Chile [53]

“Programa Materno Infantil” (Maternal infant program)

The maternal-infant program began in 1936. The National Supplementary Feeding Program providing artificial milk also began that year. The latter two programs have reached universal coverage.

“Bono Control de Niño Sano” (Monetary subsidies for health children)

Monetary subsidies for healthy children: all families with children under 6 years old receive a money transfer equivalent to $16 \mathrm{US} \$ /$ child/month since 1953. This payment is for workers whose salary is under the minimum, for informal workers or unemployed. The conditions for receiving it are children vaccination, assistance to regular health controls and school assistance from 5 years old.

“Bono Porhijo” (Monetary subsidies by son)

Monetary subsidies by son: it is a benefit that increases the amount of the pension of women through the delivery of a bond for each live birth or adopted, it is not paid at the time of birth of the child, but rather with his pension. The bond, which is set and begins to generate revenue from the date of birth of the child and is $10 \%$ of 18 minimum monthly wages (set for workers aged 18 and 65 years old).

“Asignación prenatal” (Prenatal monetary subsidies)

Prenatal monetary subsidies: pregnant women receive a monetary allowance since 1981 provided that they assist to health controls from the 5th month of pregnancy. 


\section{Continued}

Colombia [54]

“Desayunos infantiles con amor” (Children's breakfasts with love)

Children's breakfasts with love: the aim of this program is to improve consumption of food in children between 6 months and 4 years old by providing food supplements and conduct of training, promotion and health care. With the active participation of the family, the community and the local authorities.

“Grupo de Apoyo Misional” (Missionary support group)

The "Missionary support group" objective is supporting the recovery and rehabilitation of people in situation of displacement and vulnerability. They have the focus of helping infants, toddlers, pregnant and lactating women.

“Chispitas de Vida ” (Sprinkles of life) [55]

The aim of this program is to reduce anemia among children between two to five years old by providing micronutrients powders. This program also provides deworming and health education for the families involved in the program.

“Recuperación nutricional” (Nutritional recovery)

The purpose of this program is to contribute to the recovery of the nutritional status of children less than five years old with risk of acute malnutrition by education programs and nutritional support.

“De cero a siempre” (From cero to always) [44]

National program that provides services in order to ensure an integral devel-
opment for infants up to 6 years old. Among the objectives are inclusion of
early childhood development plans in 2012 and indicators related to early
childhood (child and maternal mortality, immunization, breastfeeding, birth,
prenatal and birth care, access of children to health services and support to
child development).

The "Programa Materno Infantil" (Maternal-infant national program) in Chile has been evaluated and shown successful in the redirection of the population to the health services including maternity deliveries and vaccination coverage. The National Supplementary Feeding Program is the largest nutritional intervention in Chile, with great achievements in improving birth weight and preventing malnutrition and anemia with an undoubted contribution to significant decrease in infant and maternal mortality [42].

Finally, "Plan Nacer" (Birth Plan) shows large positive effects on birth outcomes as results of rigorous impact evaluations completed in Argentina. Specifically, impact evaluations estimate a reduction in the probability of low birth weight by $23 \%$ and birth records from larger maternity wards also show that "Plan Nacer" (Birth Plan) reduced the probability of in-hospital neonatal death by $74 \%$ for its beneficiaries. Approximately half of the reduction in deaths is attributed to better prenatal care that prevented low birth weight, while the other half is the result of better post-natal care. The program also increased the use and quality of prenatal care services as measured by the number of prenatal care visits and the probability of pregnant women receiving a tetanus vaccine [43].

In Colombia, the government creates the strategy "De cero a Siempre" (From cero to always) to provide services and ensure an integral development to infants up to 6 years old. Seventy nine percent of the departments included comprehensive development of early childhood development plans in 2012 and an increased inclusion of indicators related to early childhood (child and maternal mortality, immunization, breastfeeding, birth, prenatal and birth care, access of children to health services and support to child development) was observed when compared with previous periods [44].

\section{Discussion}

The description of some nutritional indicators in the first 1000 days of life in Colombia, Brazil, Argentina and Chile has highlighted very important aspects. Despite the inherent country differences, the nutritional challenges during the first 1000 days of life are similar. The low prevalence of exclusive breastfeeding and persistent micronutrient deficiencies such as iron, zinc and vitamin A as risk factors for morbidity and mortality in children under 3 years of age are common and therefore priority issues in the region. Among the reasons to explain these findings are that even though the 4 countries have a legal framework and policies for breastfeeding there are driving forces and barriers at the national, hospital and family levels that favor other practices such as formula and bottle use. According to the experts among the main reasons to stop breastfeeding included: 1) Hospitals not 
adhering to the baby friendly initiative and therefore hospital personnel did not provide adequate breastfeeding training and provided formula milk; 2) Inadequate breastfeeding techniques leading to mother health problems (mastitis) and unnecessary desistance of breastfeeding; 3) A relatively short maternity leave and most companies not having an adequate space for mothers to make the milk extraction and storage; 4) Mothers not having family and social support.

Persistence of anemia despite the use of fortified foods and supplementation remains a problem, and no complete data regarding sugar, sodium and fatty acids consumption and changes in the diet and habits before, during and after pregnancy are available. Inadequate prenatal care and lack of access to pre-pregnancy health check ups are among the reasons to explain the findings, however there is a clear need to make longitudinal studies in order to better understand these prevalent micronutrient deficiencies in pregnant women.

In addition, inadequate nutritional status in pregnant women could contribute to maternal and childhood morbidity and mortality during the first two years of life. Stunting, with the exception of Chile, is a public health problem in these countries, and in early life, it is associated with adverse functional consequences, including poor cognition and educational performance, low income, work capacity and, when there is an excessive weight gain later in childhood there is a higher risk of nutrition-related chronic diseases. Early interventions can prevent these outcomes [41].

The prevalence of obesity is increasing and coexists with low height for age and under nutrition in the population. This reflects the nutritional transition occurring in the region. Food programs targeted at low income stunted populations may be beneficial for some; however, they could induce obesity, especially in urban areas. Therefore, defining the right combination of foods/nutrients, education and lifestyle interventions to optimize nutrition and health are a challenge for policy-makers in Latin American countries.

There is an urgency to conduct research on the increasing prevalence of overweight and obesity in pregnancy and childhood and also to collect epidemiological information on essential fatty acids deficiency.

In addition, in order to improve the health, nutrition and well-being of all children, it is necessary to emphasize the critical importance of breastfeeding and its duration as a basic health issue for society and not just as a lifestyle choice. Furthermore, the importance of timing and quality of complementary feeding should be supported for both developmental and nutritional reasons.

Of critical importance, although there are several public health policies and programs in each country designed to impact favorably on this 1000 day period, there is a lack of unified strategies to handle all stages of malnutrition in the first 1000 days and discrepancies between perceptions of micronutrient deficiencies in pregnancy and prevention practices are still seen.

This study tried to collect the best and updated data available at the country level and therefore any comparisons or conclusions have to be interpreted taking into account the following limitations detected at country level and at the moment of comparing the 4 countries. 1 . There is a lack of a unified information system on motherchild nutrition available for policy makers, researchers and the educational system; 2 . At the country level there is inexistent or incomplete information in certain indicators (see the gap box in the result section). Information gaps were detected and these include a lack of consolidated information on food intake and food composition, scarcity and variability of the data on consumption of salt, sodium, fatty acids and dietary habits during and after pregnancy; 3 . When comparing the 4 countries, the age group or measure units were different in some indicators with data available. Also the year when the information was collected is different among countries in some of the indicators, making comparisons between countries impossible in some cases; 4 . In some cases the experts that were interviewed could not fill the information gap due to the lack of epidemiological or clinical studies, or population based surveys asking about the specific gaps.

Despite these methodological limitations and based on the literature's recommendations, studying the nutritional status during the first 1000 days of life is a public health priority at the local and regional level. Common challenges are detected in the region and therefore the study's results are relevant for nutrition and clinical experts and policy makers.

Opportunities to improve the nutritional status in these countries could include the development of a regional database with nutrition information during the 1000 days of life, active communication and dissemination of nutrition indicators readily available for policies makers, researchers and academy would be useful to spread its relevance, share best practices and nutrition programs.

Also the continuous evaluation of nutrition and health programs and the development of fortified foods to improve micronutrient intake (iron, folic acid, essential fatty acids, calcium and vitamin D) and to contribute to a diet diversification in pregnant women and children under 2 years of age. 


\section{Conclusions}

In relation to the experts opinions, summarizing and concluding the results relate to breastfeeding: 1) there is the need to address breastfeeding barriers encountered in health institutions (newborns are fed with other foods) especially in the first hours and day of birth; 2) It is fundamental to ensure that general physicians, pediatricians, gynecologists, nurses and any health professional that are related in childbirth are trained in breastfeeding recommendations and help implement breastfeeding programs and policy; 3) It is important to encourage a complete exclusive breastfeeding period of 6 months to prevent disease and reduce childhood mortality; 4) It is important to implement evaluation and follow up of breastfeeding practices in health institutions; 5) It is fundamental to promote collaboration between health institutions, academy and government.

In relation to maternal and child micronutrient supplementation, it is crucial to address maternal micronutrient deficiencies with specific recommendations of foods for pregnant women and for childbearing women (preconception period) with Iron, Folate, essential fatty acids, Calcium, Vitamin D. Also, addressing children micronutrient deficiencies with specific recommendations of food that improve the intake of key nutrients and food verification for children below 2 years old.

The recommendation for health professionals would be to establish official recommendations or position from pediatric societies about age for cow's milk and complementary feeding introduction and development of clinical practice guidelines on pro and prebiotics consumption.

Finally, for Government and academicsocieties, it would be interesting to develop a unified information system on mother-child nutrition available for policy makers, researchers and the educational system at the regional and national level.

\section{Acknowledgements}

Brazil, Chile, Argentina and Colombia Nutripack teams, Dr. Eugenia Maciero and Lic. Débora Cedro. Jenny Milena Machetá from Academia Nacional de Medicina, Diego Prieto and Giovanni Pulido from the Universidad de los Andes Library.

\section{References}

[1] Adair, L.S. (2014) Long-Term Consequences of Nutrition and Growth in Early Childhood and Possible Preventive Interventions. Nestle Nutrition Institute Workshop Series, 78, 111-120. http://dx.doi.org/10.1159/000354949

[2] Canani, R.B., Di Costanzo, M., Leone, L., Bedogni, G., Brambilla, P., Cianfarani, S., et al. (2011) Epigenetic Mechanisms Elicited by Nutrition in Early Life. Nutrition Research Reviews, 24, 198-205. http://dx.doi.org/10.1017/S0954422411000102

[3] Delisle, H. (2001) [Foetal Programming of Nutrition-Related Chronic Diseases]. Sante, 12, 56-63.

[4] Langley-Evans, S.C. and McMullen, S. (2009) Developmental Origins of Adult Disease. Medical Principles and Practice: International Journal of the Kuwait University, Health Science Centre, 19, 87-98. http://dx.doi.org/10.1159/000273066

[5] Organization, W.H. Breast Feeding Recomendations. http://www.who.int/topics/breastfeeding/en/

[6] Alles, M., Eussen, S., Ake-Tano, O., Diouf, S., Tanya, A., Lakati, A., et al. (2013) Situational Analysis and Expert Evaluation of the Nutrition and Health Status of Infants and Young Children in Five Countries in Sub-Saharan Africa. Food \& Nutrition Bulletin, 34, 287-298. http://dx.doi.org/10.1177/156482651303400301

[7] Wardlaw, T.M. (2004) Low Birthweight: Country, Regional and Global Estimates: UNICEF. http://www.unicef.org/publications/index_24840.html

[8] Bhutta, Z.A. and Black, R.E. (2013) Global Maternal, Newborn, and Child Health-So Near and Yet so Far. New England Journal of Medicine, 369, 2226-2235. http://dx.doi.org/10.1056/NEJMra1111853

[9] Bhutta, Z.A., Das, J.K., Rizvi, A., Gaffey, M.F., Walker, N., Horton, S., et al. (2013) Evidence-Based Interventions for Improvement of Maternal and Child Nutrition: What Can Be Done and at What Cost? The Lancet, 382, 452-477. http://dx.doi.org/10.1016/S0140-6736(13)60996-4

[10] Rivera, J.A., Barquera, S., Gonzalez-Cossio, T., Olaiz, G. and Sepulveda, J. (2004) Nutrition Transition in Mexico and in Other Latin American Countries. Nutrition Reviews, 62, S149-S157. http://dx.doi.org/10.1111/j.1753-4887.2004.tb00086.x

[11] Miranda, J.J., Kinra, S., Casas, J.P., Davey Smith, G. and Ebrahim, S. (2008) Non-Communicable Diseases in Lowand Middle-Income Countries: Context, Determinants and Health Policy. Tropical Medicine \& International Health, 
13, 1225-1234. http://dx.doi.org/10.1111/j.1365-3156.2008.02116.x

[12] Uauy, R., Albala, C. and Kain, J. (2001) Obesity Trends in Latin America: Transiting from Under- to Overweight. The Journal of Nutrition, 131, 893S-899S.

[13] WHO Joint and FAO Expert Consultation (2003) Diet, Nutrition and the Prevention of Chronic Diseases. http://apps.who.int/iris/bitstream/10665/42665/1/WHO_TRS_916.pdf

[14] Barria, R.M. and Amigo, H. (2006) Nutrition Transition: A Review of Latin American Profile. Archivos Latinoamericanos de Nutrición, 56, 3-11.

[15] Bermudez, O.I. and Tucker, K.L. (2003) Trends in Dietary Patterns of Latin American Populations. Cadernos de Saúde Pública, 19, S87-S99. http://dx.doi.org/10.1590/S0102-311X2003000700010

[16] Llanos, A., Teresa Oyarzún, M., Bonvecchio, A., Rivera, J.A. and Uauy, R. (2008) Are Research Priorities in Latin America in Line with the Nutritional Problems of the Population? Public Health Nutritio, 11, 466-477. http://dx.doi.org/10.1017/S1368980007000730

[17] Health Mo (2007) Encuesta Nacional de Nutricion y Salud (ENNYS). Argentina. http://datos.dinami.gov.ar/produccion/nutricion/ennys.html

[18] Ministerio de Salud DdEeIeS, Chile (2010). http://www.minsal.cl/

[19] Profamilia Asociación Probienestar de la Familia Colombiana (2010) Encuesta Nacional de Demografía y Salud (ENDS). https://dhsprogram.com/pubs/pdf/FR246/FR246.pdf

[20] Saúde Md (2009) Pesquisa Nacional de Demografia e Saúde (PNDS). Brasil. http://bvsms.saude.gov.br/bvs/pnds/index.php

[21] Nación MdSdl (2013) Encuesta Nacional de Factores de Riesgo 2013. Argentina. http://www.msal.gov.ar

[22] The United Nations Children’s Emergency Fund (2015) Nutrition Indicators. http://www.unicef.org/progressforchildren/2006n4/index_lowbirthweight.html

[23] The World Bank (2015). http://data.worldbank.org/indicator/NY.GDP.PCAP.CD

[24] Ministério da Saúde B (2012) Red Interagencial de informacoes para a saúde. Indicadores e dados basicos. http://tabnet.datasus.gov.br/cgi/idb2012/matriz.htm-demog

[25] Inmunizaciones PAd (2015) Programa Ampliado de Inmunizaciones. http://www.minsalud.gov.co/salud/Paginas/ProgramaAmpliadodeInmunizaciones(PAI).aspx

[26] Ministério da Saúde B. Gestação de alto Risco 2015. http://bvsms.saude.gov.br/bvs/publicacoes/gestacao_alto_risco.pdf

[27] Villar, J., Valladares, E., Wojdyla, D., Zavaleta, N., Carroli, G., Velazco, A., et al. (2006) Caesarean Delivery Rates and Pregnancy Outcomes: The 2005 WHO Global Survey on Maternal and Perinatal Health in Latin America. The Lancet, 367, 1819-1829. http://dx.doi.org/10.1016/S0140-6736(06)68704-7

[28] Atalah, E. and Castro, R. (2004) Obesidad materna y riesgo reproductivo. Revista Medica de Chile, 132, 923-930. http://dx.doi.org/10.4067/S0034-98872004000800003

[29] Yang, Z. and Huffman, S.L. (2013) Nutrition in Pregnancy and Early Childhood and Associations with Obesity in Developing Countries. Maternal \& Child Nutrition, 9, 105-119. http://dx.doi.org/10.1111/mcn.12010

[30] Muzzo, B. (2002) Evolución de los problemas nutricionales en el mundo: El caso de Chile. Revista Chilena de Nutrición, 29, 78-85.

[31] Calvo, E.B. and Biglieri, A. (2008) Impact of Folic Acid Fortification on Women's Nutritional Status and on the Prevalence of Neural Tube Defects. Archivos Argentinos de Pediatrí, 106, 492-498.

[32] Familiar Instituto Colombia de Bienestar (2010) Encuesta Nacional de Situación Nutricional en Colombia (ENSIN). http://www.icbf.gov.co/portal/page/portal/PortalICBF/Bienestar/ENSIN1

[33] Agudelo Gill, M.L., Castaño Castrillón, J.J., et al. (2010) Prevalencia de trastornos hipertensivos en mujeres embarazadas controladas en Assba Salud, Manizales, Colombia. 2006-2008. Archivos de Medicina, 10, 139-150.

[34] Albala, C., Vio, F., Kain, J. and Uauy, R. (2001) Nutrition Transition in Latin America: The Case of Chile. Nutrition Reviews, 59, 170-176. http://dx.doi.org/10.1111/j.1753-4887.2001.tb07008.x

[35] DC. T. Diabetes en Colombia, Descripción de la epidemiología actual. http://www.odc.org.co/files/Diabetes_en_Colombia_descripcion_de_la_epidemiologia_actual.pdf

[36] Saúde Md. Pesquisa Nacional de Demografia e Saúde da Criança e da Mulher (PNDS) (2006). http://bvsms.saude.gov.br/bvs/pnds/index.php

[37] Organization WHO (2003) Community-Based Strategies for Breastfeeding Promotion and Support in Developing 
Countries. http://www.who.int/maternal_child_adolescent/documents/9241591218/en/

[38] Ministerio da Saúde B (2015) National Iron suplementation program Brasil. http://www.saude.gov.br/nutricao

[39] Ministerio da Saúde B (2015) Vitamin A suplementation program Brasil. http://www.saude.gov.br/nutricao

[40] Varea, A., Malpeli, A., Etchegoyen, G., Vojkovic, M., Disalvo, L., Apezteguía, M., Pereyras, S., Pattín, J., Ortale, S., Carmuega, E. and Gonzalez, H.F. (2011) Short-Term Evaluation of the Impact of a Food Program on the Micronutrient Nutritional Status of Argentinean Children Under the Age of Six. Biological Trace Element Research, 143, 1337-1348. http://dx.doi.org/10.1007/s12011-011-8978-0

[41] De Onis, M. Blössner, M. and Borghi, E. (2012) Prevalence and Trends of Stunting among Pre-School Children, 1990-2020. Public Health Nutrition, 15, 142-148. http://dx.doi.org/10.1017/S1368980011001315

[42] Cotta, R.M.M. and Machado, J.C. (2013) Programa Bolsa Família e segurança alimentar e nutricional no Brasil: Revisão crítica da literatura. Revista Panamericana de Salud Pública, 33, 54-60. http://dx.doi.org/10.1590/S1020-49892013000100008

[43] The World Bank (2012) Argentina’s Plan Nacer: Delivering Results for Mothers and Their Children. http://www.worldbank.org/en/topic/health/brief/argentinas-plan-nacer-delivering-results-for-mothers-and-their-childre $\underline{\mathrm{n}}$

[44] Colombia Gd (2016) Programa de Cero a siempre. http://www.deceroasiempre.gov.co/Paginas/deCeroaSiempre.aspx

[45] Measham, A. (2009) Argentina: Plan Nacer. http://www.rbfhealth.org/resource/argentina-plan-nacer

[46] Ministry of Health. Programa SUMAR, la ampliación del Plan Nacer Argentina. http://www.msal.gov.ar/sumar/images/stories/pdf/brochure.pdf

[47] Ministry of Health. Asignacion Universal por hijo Argentina. http://www.anses.gob.ar/prestacion/asignacion-universal-por-hijo-92

[48] Ministry of Health. Programa Materno Infantil Argentina. http://www.msal.gov.ar/dinami/index.php/info-ciudadanos/informacion-integral

[49] Ministry of Health. National Iron Suplementation Program Brasil. http://www.saude.gov.br/nutricao

[50] Ministry of Health. Vitamin A Suplementation Program Brasil. http://www.saude.gov.br/nutricao

[51] Ministry of Health. Stork Network (Rede Cegonha) Brasil. http://www.ciespi.org.br/primeira_infancia/leis-e-politicas/programas

[52] Ministry of Health. Healthy Brazilians (Brasileirinhas e Brasileirinhos Saudáveis: Primeiros Passos para o Desenvolvimento Nacional) Brasil. http://www.ciespi.org.br/primeira_infancia/leis-e-politicas/programas

[53] Ministry of Social Development. Misión Institucional Chile. http://www.chileatiende.cl/servicios/ver/AI000

[54] National Planning Department (DNP) (2012) Manual de la oferta Institucional del Gobierno hacia las Entidades Territoriales. http://www.dnp.gov.co/LinkClick.aspx?fileticket=aQI_yNEwnKk\%3d\&tabid=381

[55] World Food Program (2014) The “Chispitas de vida” Programme Colombia. http://wfp.exposure.co/colombia 